\title{
EL ART. 348 DEL CÓDIGO CIVIL DE 1984 O LA SUPERSTICIÓN DEL DIVORCIO
}

\author{
ART. 348 OF THE 1984 CIVIL CODE OR SUPERSTITION OF \\ THE DIVORCE
}

\author{
Ramiro De Valdivia Cano ${ }^{1}$ \\ "El divorcio disuelve el vínculo del matrimonio." \\ Art. 348 del Código Civil del Perú
}

\section{Resumen}

El título de este ensayo alude en primer lugar a la norma positiva que rige la institución del divorcio en el Perú: el art. 348 del Código Civil. Esta norma es ampliamente desarrollada en el Código y en sucesivas leyes que han ido ampliando el ámbito del divorcio hasta incluir causales que contradicen la lógica y el sentido común. Alude en segundo lugar a lo que Gilbert K. Chesterton denomina la "superstición del divorcio": la perversa tesis que sustenta que el divorcio es la panacea para todos los problemas que surgen en las relaciones de familia.

El autor sostiene que por razones de índole legal, ética, social, política y antropológica, el Estado y la sociedad están obligados a promover y defender el matrimonio y la familia; y el carácter indisoluble del matrimonio.

\section{Palabras Clave}

Matrimonio, divorcio, Constitución, Código Civil.

\begin{abstract}
The title of this essay refers primarily to the positive rule governing the institution of divorce in Peru: the art. 348 of the Civil Code. This rule is widely developed in the Code and subsequent laws have being expanded the scope to include causal divorce that contradicts logic and common sense. Besides, it refers to what Gilbert K. Chesterton called "superstition divorce": the perverse argument that states divorce is the panacea for all problems in family relationships.
\end{abstract}

El autor es Profesor de la Universidad Católica de Santa María de Arequipa y de la Academia de la Magistratura del Perú. Es Juez de la Corte Suprema del Perú. 
The author argues that for reasons of legal, ethical, social, political and anthropological nature, the state and society are obliged to promote and defend marriage and the family; and the indissoluble character of marriage.

\section{Key Words}

Marriage, divorce, Constitution, Civil Code.

\section{PRÓlOGO}

La familia, la unidad básica de la sociedad, se está desmembrando. La sociedad se está desmembrando con ello. "Casi nadie (fuera de cierta prensa de carácter religioso) se atreve a defender la familia. El mundo a nuestro alrededor ha aceptado un sistema social que niega la familia. Ayudará a veces al niño, en lugar de a la familia; a la madre, en lugar de a la familia, al abuelo, en lugar de a la familia. No ayudará a la familia." (énfasis nuestro) (G.K. Chesterton en G.K.'s Weekly, 20 sept., 1930). ${ }^{2}$ La admonición se ha convertido en una profecía que se viene cumpliendo en el Perú del s. XXI, -el Perú de la Civilización del Espectáculo. Es en este punto que confluyen dos de los escritores más leídos y decisivos en Arequipa. Alguien, o muchos de sus seguidores podrían encontrarlos contradictorios, incluso incompatibles: Gilbert Keith Chesterton, (Londres, Mayo, 29 de 1874 - 14 Junio 1936) y Mario Vargas Llosa (Arequipa, Marzo, 28 de 1936 ----). Pero los hermana el uso de una profunda preocupación por la sociedad a la que pertenecen; preocupación que brilla como un potente faro de humanidad y compasión

La cita de Borges que abre La Civilización del Espectáculo, de Vargas Llosa es una de las claves: «Nuestro hermoso deber es imaginar que hay un laberinto y un hilo». Es el hilo de la madeja de Chesterton, que une los laberintos en los que se ve abocado el Perú de hoy con las peripecias del Código Civil de 1984, con sus desarrollos e inflamaciones.

Para ilustrar este escenario apocalíptico, nada mejor que recurrir al ilustre arequipeño Mario Vargas Llosa. En verdad es plenamente aplicable a la actual institución del divorcio peruano los conceptos y términos del primer capítulo de La Civilización del Espectáculo, en el que Vargas Llosa hace un

Alquist, Dale (2012) A Prophetic Look http://www.Chesterton.org/wordpress/tag/dale-ahlquist/ Wednesday, February 22. 
preciso comentario referido a la evolución del arte moderno y la miríada de experimentos que lo nutren, para concluir que «...ya no existe criterio objetivo alguno que permita calificar o descalificar una obra de arte, ni situarla dentro de una jerarquía; posibilidad que se fue eclipsando a partir de la evolución cubista y desapareció del todo con la no figuración... " ${ }^{3}$. No es difícil caer en la tentación de la extrapolación de esta crítica al mundo artístico, para aplicarla al del Derecho.

En sus ramas Constitucional y de Familia también se puede afirmar que, a falta de criterios coherentes, en el derecho positivo peruano, todo puede ser llamado « Derecho » o que nada lo es, según el úkase y compromisos de quienes manejan el poder mediático. Este poder, ha sido elevado, en razón del naufragio de todos los patrones jurídicos y éticos, al nivel de árbitro y juez implacable y definitorio. Sus fallos son inapelables. Esta situación ha devenido en una expresión del carácter paradójico de la democracia. Entre sus más manifiestas expresiones se halla la promoción del aborto y del divorcio, presto a ser consagrado como "derecho fundamental", que hacen exclamar en contextos similares al peruano: "Parece mentira que un jurista hable de 'derecho' al aborto cuando no existe esa calificación jurídica en ningún tratado internacional ni en declaración alguna de derechos humanos", tal como ha recriminado la portavoz de Derecho a Vivir, Gádor Joya ${ }^{4}$. Es exactamente igual lo que se puede decir del proclamado "derecho fundamental" al divorcio. Ésta convocatoria advierte que la democracia, más allá de los meros ideales y discursos políticos, es una lucha constante contra lo intolerable. Es más, cuando se convierte en un sistema de valores de consumo, sin crear un sentido de la responsabilidad, se aniquila al convertirse en una comunidad regida por la mediocridad.

Lo cual trae a colación la complejidad, la espontaneidad, la heterogeneidad y, más aún, la perfectibilidad de la democracia que hacen que el sistema democrático nunca satisfaga a cabalidad. La plena satisfacción equivaldría a olvidar su propia esencia como esfuerzo cotidiano de responsabilidad cívica; puesto que la libertad y la democracia no se constriñen a satisfacer deseos ya que carecen de sentido cuando obliteran el horizonte de la responsabilidad ética. Al respecto, Václav Havel, el político, escritor y dramaturgo checo, propone que el sistema democrático se basa en la confianza en el sentido de la responsabilidad del ser humano. Por lo tanto, la democracia y la libertad deben despertar y cultivar ese sentido

Vargas Llosa, Mario (2012) La civilización del espectáculo. Lima Edit. Alfaguara. Pág. 16.

https: / /HazteOir.org/posts/294437097375029? Febrero, 26, 2014 
de responsabilidad. Esa es una clave muy importante de la identidad del demócrata.

Ante la expedición de normas formalmente legales que atacan el matrimonio y la familia, se debe alzar este sentido de la responsabilidad común ante lo intolerable; en nombre de la dignidad y la vulnerabilidad del ser humano. Siendo la democracia una creación humana, siempre puede ser optimizada y siempre será perfectible y, mientras tanto, el demócrata nunca estará enteramente satisfecho con la democracia en tanto valor filosófico y realidad política. Después de todo, la democracia es obra humana y su suerte está sometida a la condición humana.

Como puede concluirse, el único criterio más o menos generalizado en el mundo de la legalidad, en las primeras décadas del s. XXI, no tiene nada jurídico. Ese criterio es el impuesto por un mercado intervenido y manipulado por mafias transnacionales y sus agentes locales que, de ninguna manera, revela teorías ni sensibilidades jurídicas. Se trata sólo de un experto manejo de operaciones publicitarias, de relaciones públicas y, en muchos casos, de simples atracos.

Más aún, en áreas tan importantes como la de los derechos de la familia y el derecho a la vida, se ha hecho común, corriente y aceptable caer en el bochorno de pretender resolver los problemas desde la casuística, desde la coyuntura excepcional o exótica. Para lograrlo, se utiliza las imperfecciones del sistema democrático que conlleva el uso equívoco de las facultades legislativas ${ }^{5}$. Este es un cotidiano error que, al estilo farisaico, busca la simplificación y la pauperización de lo que es trascendente. Por sí sola, la democracia es insuficiente; y la convocatoria a elecciones y la aprobación de leyes pueden convertirse en meros rituales, cuando no en verdaderos ataques a los Derechos Fundamentales. Se necesita algo más: autoexploración e intercambio dialógico.

Las tesis de la civilización del espectáculo o del consumismo, tampoco habrían encontrado puertas abiertas en ningún ámbito jurídico serio. El espectáculo, haciendo el traslado al campo de las artes visuales, resulta tan vulgar, farsesco y desolador como la exposición de la Royal Academy que visitó (por última y defintiva vez) don Mario Vargas Llosa pero multiplicado por cien. Una patética mojiganga, donde, bajo la coartada de la modernidad,

Véase la Ley 29227 de 16 de mayo del 2008, Ley que regula el procedimiento no contencioso de la separación convencional y divorcio ulterior en las municipalidades y notarías. Y su reglamento, aprobado por Decreto Supremo $\mathrm{N}^{\circ}$ 009-2008- JUS. 
el experimento, la búsqueda de «nuevos medios de expresión», en verdad se documenta la terrible orfandad de respeto a los Derechos Humanos; orfandad de autenticidad e integridad.

\section{EL ARTÍCULO 348 DEL CÓDIGO CIVIL DEL PERÚ}

El domingo 14 de setiembre del 2014, el Papa Francisco concelebró el matrimonio de 20 parejas de la diócesis de Roma, en la Basílica de San Pedro. En su homilía, el Santo Padre aseguró que "el matrimonio es símbolo de vida, de la vida real. No es una 'novela'".

El Santo Padre indicó que nunca la familia cristiana y el matrimonio han sido atacados tan duramente como lo son en la actualidad; y que la celebración "nos hace pensar también en las familias, en nuestras familias en camino, por los derroteros de la vida, por las vicisitudes de cada día". El pontífice subrayó que "el amor de Cristo puede devolver a los esposos la alegría de caminar juntos; porque eso es el matrimonio: un camino juntos de un hombre y una mujer, en el que la mujer tiene la misión de ayudar a su marido a ser más hombre". "Esta es la misión que tienen entre ustedes", indicó el Papa. "Es la reciprocidad de la diferencia. No es un camino llano, sin problemas, no, no sería humano. Es un viaje comprometido, a veces complicado, pero así es la vida"... "...y así se sigue caminando. El matrimonio es símbolo de vida, de la vida real, no es un 'novela'. Es el sacramento del amor de Cristo y de la Iglesia, un amor que encuentra en la Cruz su prueba y su garantía".

El mensaje y, aún, el evento papal dan razón de la trascendental importancia de la institución del matrimonio en el mundo de hoy.

Cada familia tiene una identidad inconfundible, identidad que es el hábitat en el que se desarrolla la identidad individual de sus integrantes. Es así que los niños necesitan instintivamente sentirse pertenecientes a una familia; y los miembros de esa familia no pueden ser comprendidos aislados unos de otros. La continuidad, el grado de satisfacción emocional, los desafíos y la estabilidad familiares, la conducta de cada uno, las interacciones, la comunicación (tanto la verbal como la no verbal) y los cambios en el interior de la familia repercuten en la unidad psíquica, física y espiritual que es cada uno de sus integrantes. Ante el hecho traumático del divorcio de sus padres, el niño carece de recursos.

Este problema tiene en el Perú, una respuesta legal específica: El divorcio.El art. 348 del Código Civil. Cuando alguno de los cónyuges, o ambos, 
acceden a los estrados de la magistratura en busca de solución a sus problemas conyugales, se ha hecho un lugar común, proponer que todos los avatares que confronta una familia, reales o supuestos, pequeños o grandes serán automáticamente solucionados cuando el juez (o el Notario o el funcionario municipal) digiten las frases sacramentales de la disolución del vínculo matrimonial. Esa es una superstición, con todos los contornos con que Gilbert K. Chesterton expresa esta parábola. En los antiguos cuentos de hadas, la superstición llevaba a la firme creencia que aseguraba que todos los problemas y tragedias se solucionarían en el momento en el que la heroína del cuento y su Príncipe Azul se casaban con él. La sociedad moderna ha forjado la moderna superstición del divorcio.

La superstición del divorcio se expresa nítidamente en el art. 348 del C.C. y en los sucesivos desarrollos, más claramente aún en aquellas normas que entregan a Notarios y a funcionarios municipales la gravísima facultad de autorizar el divorcio. $\mathrm{O}$ aquellas nuevas y delirantes causales de divorcio. Esta respuesta legal es otro paradigma del concepto de Derecho inscrito en el modelo del Derecho codificado, el modelo jurídico clásico que mantiene las representaciones canónicas de los juristas y que conserva duras formas de aplicación práctica; el que pretende inscribirse en un depósito sagrado, tablas de la ley o códigos y constituciones modernas siempre proferido desde arriba que adopta la forma de ley, forjado en la edad moderna; el Derecho que tiene como íconos la pirámide, la ley escrita, el Juez identificado como "hombre de leyes" o "la boca de la ley". La soberanía del legislador asume las connotaciones laicas de la suprema potestas divina, las cuales lo capacitarían “... para desvelar las mejores reglas de la sociedad". El mismo Juan Jacobo Rousseau, en su Contrato Social, digitó el perfil de ese legislador que tendría: “...una inteligencia superior que viera todas las pasiones de los hombres, que no tuviera ninguna relación con nuestra naturaleza y la conociera a fondo, cuya suerte fuera independiente de nosotros y, por tanto, quisiera ocuparse bien de lo nuestro, que en el progreso de los tiempos se procurara una gloria lejana; que pudiera trabajar en un siglo y gozar en otro..." 6

Aunque Rousseau, sentenció que para la plasmación cabal de este modelo haría falta dioses que pudiesen dar leyes a los hombres, el mismo Kelsen, hubo de reconsiderar el estatus de su teoría fundamental, admitiendo que una norma legal es más que una hipótesis intelectual ya que debe necesariamente expresar el significado de un acto de voluntad.

Rousseau, Jean-Jacques (1972) Du contrat social: Des principes du droit politique, París. 
A la luz de estas propuestas, se puede encontrar que el devenir y el desarrollo del art. 348 del C.C. parte de suponer vigencia de una norma fundamental lo cual también significa suponer la existencia de una "autoridad imaginaria" que "quiere" esa norma. Esto es, sin duda, una ficción, pero una ficción necesaria para la validación positivista de los órdenes jurídicos en vigor. Los resultados de la vigencia de estas teorías son dramáticos. Ya el año 2010, a dos años de haber entrado en vigencia el conocido 'divorcio rápido' o 'divorcio express', la demanda para acceder a este trámite viene superando en $25 \%$ a las solicitudes de matrimonio en el distrito limeño de Jesús María. Según los funcionarios de la Gerencia de Asesoría Jurídica y Registros Civiles de dicha comuna "Mientras que más de 1.200 parejas disolvieron su vínculo matrimonial, apenas 890 decidieron unir sus vidas". Incluso, un $50 \%$ de personas que decide romper el vínculo marital lo hacen a través de terceras personas, mediante una carta poder. ${ }^{7}$ De acuerdo con los resultados de las últimas Encuestas Demográficas y de Salud Nacional (Endes), sólo en la década 2000- 2010, los divorcios y separaciones se incrementaron en un $51,52 \%$. Las bodas sólo aumentaron en $1.25 \%$.

Ahora bien, según el Instituto Nacional de Estadística e Informática (INEI), hasta antes del 2009 el rango de edades de las personas que más se separan o divorcian estaba entre los 45 y 49 años. Pero los resultados, a partir del 2010 arrojan que esta edad ha bajado y ahora, los que más se divorcian o separan están entre los 40 a 45 años. La tendencia es que se divorcien cada vez más jóvenes", afirma el Instituto de Ciencias del Matrimonio. "Si se indaga en las razones de esta gran diferencia entre el crecimiento de los divorcios y matrimonios se tiene por ejemplo los resultados de una encuesta hecha por la Universidad de Lima. Esta revela que entre los principales problemas que las parejas identifican están, en primer lugar, la falta de comunicación (35\%), seguida de los problemas económicos (24\%) y la desconfianza $(12 \%)$ ". "De hecho, desde que salió la ley del divorcio express, estaba previsto que se iban a incrementar. La norma ha facilitado un procedimiento que antes era demasiado complicado", opina esta vez el psicólogo Manuel Saravia, quien ha tratado numerosos problemas de pareja en el Instituto Gestalt de Lima ${ }^{8}$.

Estas son unas pinceladas de cómo ha evolucionado el Art. 348 del C.C. de 1984, cuyos autores habrían alucinado una meta positiva que se fue eclipsando a partir de la evolución cubista y desapareció del todo con la no

http:/ / elcomercio.pe/lima/sucesos/solicitudes-divorcio-superan-matrimonio-municipalidad-jesus-marianoticia-486237 Consultado el 27 de mayo del 2010.

http:/ / www.larepublica.pe/04-11-2011/divorcios-aumentaron-hasta-en-mas-de-50 
figuración, incluyendo sus productos icónicos: las leyes que han introducido el divorcio "fast track" o divorcio express, que promueve las demandas de divorcio fundamentadas en punible hecho propio, y el divorcio que faculta a Notarios y funcionarios municipales a dictar sentencias de divorcio. Todo ello en frontal colisión con lo que establecen los Arts. $4^{\circ 9}$ y 139.1 de la Constitución ${ }^{10}$ Política, así como con el Art. VI del T.P. ${ }^{11}$ y Art. 335 del Código Civil. ${ }^{12}$

Pero, advirtamos que este lamentable proceso de pauperización de los conceptos de vida, familia y de matrimonio se da en el contexto de un sistema democrático. La violencia que importa el aborto, el divorcio, el fútbol profesional muestran la corrupción del sistema democrático. Este contexto refleja la relevancia de las lecciones de John Dewey, según las cuales la política es solamente la sombra que arrojan las grandes corporaciones sobre la sociedad. Las normas legales que relativizan, cuando no los atacan frontalmente, los valores de la vida humana, la familia y el matrimonio son la etiología de un grave problema de corrupción en el sistema democrático. Esa corrupción del sistema constituye un problema inquietante porque surge en el seno de la democracia y atañe a algo concreto: la legitimidad de la violencia. El aborto, el divorcio (más aún el divorcio frívolo), el desamparo del sistema educativo desde el Estado son muestras de la legitimación de la violencia.

Al reconocimiento de esta etiología y la posibilidad de que las democracias degeneren en violencia se agrega un mal mayor -la apatía con la que esta violencia estatal es recibida en la comunidad jurídica. En consecuencia, pese a la gravedad de esta forma de corrupción, la civilización del espectáculo ha logrado que la sociedad pase por alto el carácter paradójico de los nuevos frutos de la propia democracia. Siendo la democracia un proceso por el cual se domeña la violencia, hoy en día se acepta que los Estados y las sociedades democráticos también generen violencia y la legalicen.

Constitución Política del Perú.- CAPITULO II.- DE LOS DERECHOS SOCIALES Y ECONOMICOS

Artículo 4.- Protección a la familia. Promoción del matrimonio

La comunidad y el Estado protegen especialmente al niño, al adolescente, a la madre y al anciano en situación de abandono. También protegen a la familia y promueven el matrimonio. Reconocen a estos últimos como institutos naturales y fundamentales de la sociedad.

La forma del matrimonio y las causas de separación y de disolución son reguladas por la ley. (SPIJ (Actualizado al 30 de Marzo de 2011) )

10 Constitución Política del Perú.- Art. $139^{\circ}$ Principios de la función jurisdiccional.-

Son principios y derechos de la función jurisdiccional:

1.- La unidad y exclusividad de la función jurisdiccional.

No existe ni puede establecerse jurisdicción alguna independiente, con excepción de la militar y la arbitral.

No hay proceso judicial por comisión o delegación.

11 Código Civil del Perú. Título preliminar.- Art. VI.- Interés para obrar.- Para ejercitar o contestar una acción es necesario tener legítimo interés económico o moral...

12 Código Civil del Perú.- Hecho propio.- Ninguno de los cónyuges puede fundar la demanda (de divorcio) en hecho propio. 
Cuantos más instrumentos violentos desarrolle una comunidad democrática, menos podrá resistirse al mal de la corrupción del sistema. Quizá sea esta razón de que, para la democracia, la no violencia sea una salvaguarda más valiosa y cuya necesidad sea más perentoria. Pero hay que exigir no sólo ausencia de violencia y garantías instituciones, sino también responsabilidad de parte de todos.

Ante la violencia que ejerce el Estado, se requiere rechazar sus ataques contra la vida, la familia y el matrimonio; y el establecimiento de garantías institucionales opuestas a la lógica del Estado.

\section{EL MATRIMONIO ES SÍMBOLO DE LA VIDA}

Gilbert K. Chesterton ya lo denunció a comienzos del s. XX: la comunidad humana ha entrado en una fase de erosión dirigida al establecimiento de una sociedad sin familia ${ }^{13}$. Debido a la misma existencia del divorcio y su promoción estruendosa, la familia ya está atravesando una crisis muy seria. Los jóvenes prefieren no formar familias y las frecuencias del divorcio tienden a superar las del matrimonio ${ }^{14}$. Las familias separadas acusan proyectos de vida fracasados y los hijos llevan sobre sus espaldas el sufrimiento de las consecuencias de la separación. Ante el hecho traumático del divorcio, los hijos carecen de recursos.

\section{LEY, FAMILIA Y MATRIMONIO}

Al monitorear la evolución del divorcio en el Perú se percibe que la racionalización del modelo jurídico peruano propone la idea de reunir todo el material jurídico en un código unitario sistematizado, coherente y manejable. Más aún, se advierte que en la formación de la constitución histórica, y hasta la Declaración de los Derechos Humanos (1948), la cuestión sobre los fundamentos de la legislación parecía clara. Pero, en las últimas décadas se da un cambio paulatino. Ante el conjunto social, el Derecho Natural -y su ejecutoria en contra de la injusticia, la violencia y la desigualdad instaladas en la sociedad en contra del matrimonio y la familia- es caracterizado como una doctrina católica más bien singular, sobre la que no vale la pena discutir fuera del ámbito católico, de modo que invocarlo suena a majadería o ingenuidad.

13 N.A. En lo que coincide con un espíritu tan disímil al suyo como es el de George Orwell, el autor de la portentosa novela Mil Novecientos Ochentaicuatro.

14 En Ecuador, la tasa de divorcios ha crecido un $69 \%$ en 10 años, según cifras del INE; la población aumentó en 3 millones de personas, pero la tasa de bodas permaneció estancada. En Uruguay, la tasa de divorcios ya superó en el 2013 la tasa de matrimonios. 
Se ha llegado, en materia de divorcio, a una simplificación radical del material jurídico a la mano. Se ha hecho obliteración de normas constitucionales y del mismo Código Civil (el divorcio fundamentado en causa propia), bajo la supuesta inspiración de nuevas concepciones sociales. El legislador, más bien, frívolamente, acaba reescribiendo categorías que tienen tanta trascendencia como la familia y el matrimonio. De esta forma, casi nadie lo hace; pero quien denuncia las políticas que promueven el envilecimiento de la familia y del matrimonio, lo que se propone hacer es sustentar principios para crear un entorno cultural y político que sea compatible con la vida, la libertad y la esperanza para el futuro y, además, expresar, de modo razonado, propuestas dirigidas a que las normas legales que están vinculadas con los Derechos de la Familia sean acordes con la verdad del amor humano. A contrapelo de lo que pregona la civilización del espectáculo, estas denuncias reafirman que la familia natural es la unidad fundamental de la sociedad. Que no lo es el individuo.

No se trata de imponer nada a nadie, como a veces se dice erróneamente con ánimo de desacreditar esas denuncias. En todo caso, el planteamiento es claro: La familia natural es el sistema social óptimo. Tampoco se trata de imponer la propia fe en una sociedad -asolada por el consumismo, el ateísmo, el relativismo, el egoísmo y el hedonismo- en la que conviven multitud de convicciones y credos.

Esta denuncia es necesaria porque las políticas en boga en la civilización del espectáculo hacen día a día más recios sus ataques a la familia natural, atizando la relativización de la esencia del matrimonio y de la familia, negándole su ubicación como patrimonio común de la recta razón de la humanidad. En esas corrientes post-guerra se inscriben los cambios operados en el Perú en los campos legislativo y en el de las políticas públicas acerca de la familia. Ellos están dirigidos a corroer el significado y la dignidad de la familia y del matrimonio, a devaluar la maternidad y la paternidad. A fomentar la superstición del divorcio, las relaciones sexuales pre y extra matrimoniales, la promiscuidad, el aumento del abuso infantil. Estos cambios tienen como corolario el deterioro de la calidad de vida, la pirámide poblacional invertida y la concentración del poder. Bajo el pretexto de una libertad individual mixtificada, los cambios difunden prácticas y doctrinas que son lesivas al bien común.

\footnotetext{
Argentina, una de cada tres parejas se divorcia y el $60 \%$ de las rupturas es impulsada por las mujeres, según un estudio de María Bertoldi de Fourcade y los datos del Registro Civil de Buenos Aires.

En Europa, dos de cada tres parejas terminan en separaciones. España es el país donde más ha crecido la tasa de divorcios, según datos del Instituto de Política Familiar de ese país. Cf. http://publimetro.pe/vida-estilo/noticiatoda-vida-divorcios-aumentan-mas-rapido-que-bodas-6426
} 
En estas denuncias se debate conceptos de política social y jurídica. Precisamente porque, después del sacerdocio, la política está llamada a ser la forma más elevada de la caridad; como bien lo recordó Pablo VI desde las tribunas del Concilio Vaticano II. El fundamento sería el siguiente: Pese a que la indisolubilidad del matrimonio es asociada a la doctrina católica, los problemas, denuncias y cuestionamientos al divorcio no están enclaustrados en el ámbito religioso. Por el contrario, para el desarrollo de la humanidad, -y el del Derecho que defiende la vida y la dignidad del hombre, la familia y el matrimonio,- ha sido decisivo que los juristas católicos reconozcan que la relación entre la razón y la naturaleza es la fuente de la que brota el manantial del Derecho. Ha sido decisivo que los juristas católicos hayan tomado distancia del derecho religioso, aquel que se construye a partir de la fe; y que se hayan puesto de parte de la filosofía.

Al defender la familia y el matrimonio, en los términos que los define la Constitución, no se está blandiendo argumentos exclusivamente religiosos o católicos. La defensa de la familia y del matrimonio no es una postura religiosa, aunque coincida con la doctrina invariable de la Iglesia Católica. Hay, además, una verdad que la civilización del espectáculo pretende ocultar, infructuosamente: Tal como lo reconoce el artículo 16 de la Declaración Universal de los Derechos Humanos, "la familia es el elemento natural y fundamental de la sociedad y tiene derecho a la protección de la sociedad y del Estado". A propósito, el Sínodo 2014- 2015, de los Obispos de la Iglesia Católica sobre la Familia en el Contexto de la Evangelización definió a la familia como la célula de la convivencia humana con las características de ser: básica, necesaria y fecunda. Esta propuesta fue aprobada por 160 votos en contra de 22. Culmina con una invitación a asumir la valentía de la fe y a la acogida de la verdad en la caridad. ${ }^{15}$

El relativismo, el consumismo, el ateísmo, el egoísmo, el materialismo, el hedonismo que caracterizan la cultura del s. XXI no han podido aún demoler la familia natural porque ella se basa en la unión voluntaria de un hombre y una mujer en la alianza matrimonial de por vida. Por eso, reconocer y ayudar a esta institución es uno de los mayores servicios que el Derecho puede prestar hoy en día al bien común y al verdadero desarrollo de los hombres y de las sociedades, así como la mejor garantía para asegurar la dignidad, la igualdad y la verdadera libertad de la persona humana. En

15 Sínodo de los Obispos. III Asamblea General Extraordinaria . Los Desafíos Pastorales de la Familia en el contexto de la Evangelización. Instrumentum Laboris. Ciudad del Vaticano. 2014

https: / / www.aciprensa.com/sinodo2014/ 
resumen, asegurar la vigencia de los Derechos Humanos. Aún así, cuánta razón tiene Chesterton cuando percibe que "Habrá más, no menos, respeto por los derechos humanos si son tratados como derechos divinos." (Illustrated London News, Jan. 13, 1912).

La civilización del espectáculo está empecinada en la devastación de la familia y, en especial de la institución del matrimonio sobre todo porque familia y matrimonio tienen como objetivo la procreación y la educación de los hijos. Y porque la unión matrimonial también ofrece seguridad en tiempos de problemas; es el fundamento de una sociedad que equilibre el orden, la libertad y la solidaridad entre generaciones.

La íntima relación entre familia, sociedad y Estado "impone también que la sociedad cumpla su deber fundamental de respetar y promover la familia misma.» Estado y sociedad están llamados a garantizar y favorecer la genuina identidad de la vida familiar y a evitar y combatir todo lo que la altera y daña - respetando la prioridad y « preeminencia» de la familia. Téngase en cuenta que la histriónica normativista pretende que la realidad jurídica sea un amasijo de normas revestidas de formas constitucionales.

Ni la sociedad ni el Estado pueden, por tanto, absorber, sustituir, ni reducir la dimensión social de la familia. Esto implica superar las concepciones meramente individualistas y asumir la dimensión familiar como perspectiva cultural y política, irrenunciable en la consideración de las personas -para que Estado y sociedad sean conscientes que deben honrarla, reconocerla, respetarla y promoverla según el principio de subsidiaridad. Es así como los arts. $3^{\circ}$ y $4^{\circ}$ de la Constitución ${ }^{16}$ deben ser interpretados. Todo esto requiere la realización de auténticas y eficaces políticas acerca de las relaciones familiares, con intervenciones precisas, capaces de hacer frente a las necesidades que derivan de los derechos de la familia como tal. En este sentido, es necesario como requisito previo, esencial e irrenunciable, el reconocimiento de la identidad de la familia como sociedad natural

\footnotetext{
16 Artículo 3.- Derechos Constitucionales. Númerus Apertus

La enumeración de los derechos establecidos en este capítulo no excluye los demás que la Constitución garantiza, ni otros de naturaleza análoga o que se fundan en la dignidad del hombre, o en los principios de soberanía del pueblo, del Estado democrático de derecho y de la forma republicana de gobierno.

CAPITULO II

DE LOS DERECHOS SOCIALES Y ECONOMICOS

Artículo 4.- Protección a la familia. Promoción del matrimonio

La comunidad y el Estado protegen especialmente al niño, al adolescente, a la madre y al anciano en situación de abandono. También protegen a la familia y promueven el matrimonio. Reconocen a estos últimos como institutos naturales y fundamentales de la sociedad.

La forma del matrimonio y las causas de separación y de disolución son reguladas por la ley. (SPIJ (Actualizado al 30 de Marzo de 2011)).
} 
fundada sobre el matrimonio - lo cual comporta la tutela, la valoración y la promoción de la familia natural. El aparato estatal - como garante de la convivencia social- debería empeñarse en dictar normas que favorezcan su existencia y desarrollo.

Este reconocimiento establece una neta línea de demarcación entre la familia, entendida correctamente, y las otras formas de yuxtaposición de personas -algunas de las cuales ya han alcanzado reconocimiento en creciente número de países; especialmente en aquellos abatidos por el consumismo.

Es cierto que las personas no deben ser consideradas aisladamente sino en relación a sus propios núcleos familiares; con el añadido de sus propios valores específicos y exigencias. Por consiguiente, el reconocimiento de los derechos de la familia no se coloca como alternativa de los derechos que las personas poseen individualmente, sino más bien como su apoyo y tutela. Esta perspectiva hace posible elaborar criterios normativos para dirigirse hacia una solución correcta de los diversos problemas sociales.

Se debe tener presente, también, que la situación lamentable que en esta materia aqueja al Perú está íntimamente vinculada con la que se vive en otras latitudes. La sociedad se enfrenta ante una solapada antropología radical en la que se hace cultura a través de las leyes con el soporte del poder económico, la política y los mass media. La nueva antropología busca una re-ingeniería que tiene como íconos: consumismo, egoísmo, hedonismo, laicismo, relativismo ético. La meta aún no abiertamente declarada es la construcción de una sociedad sin familia. Ya se da los pasos previos ineludibles: La demolición de la familia, la educación mixtificada como herramienta de adoctrinamiento, la expulsión de la religión del espacio público, la deconstrucción de la sociedad.

\section{LA IMPERTINENCIA DEL ART. 348 DEL C.C.}

Para hacer cualquier propuesta acerca del contenido y alcances del art. 348 del Código Civil y las ulteriores normas de desarrollo codicial, es menester tener en cuenta que el matrimonio es una vocación que requiere preparación adecuada, discernimiento maduro y, de ser posible, un itinerario de fe. No está limitado por la tradición cultural. No es una exigencia social o jurídica. No solamente la Constitución, también la historia muestran cómo el bien de la persona y el buen funcionamiento de la sociedad están estrechamente relacionados con la prosperidad de la comunidad conyugal y familiar "... y que los que fueron los más poderosos imperios se debilitaron cuando las 
familias perdieron fuerza en la comunión y estabilidad en el compromiso."17 De allí que la defensa que se hace del divorcio como instituto jurídico resulta impertinente o irrelevante cuando se le confronta con los valores que sustentan la familia y el matrimonio y con los objetivos que estas instituciones persiguen.

Por otro lado, teniendo en cuenta las fuentes iusnaturalistas de los arts. $1^{\circ}, 2^{\circ}{ }^{18}$ y $4^{\circ 19}$ y Cuarta Disposición Final y Transitoria de la Constitución Política del Perúr ${ }^{20} ;$ y las concordantes normas contenidas en la Convención Interamericana sobre Derechos Humanos y el Pacto Internacional de Derechos Económicos, Sociales y Culturales es necesario identificar los signos distintivos del matrimonio, como trataremos de hacer a continuación; con una advertencia: Ni el Estado ni la sociedad deben soslayar la dignidad del matrimonio y de la familia en sus características específicas, que exigen ser salvaguardadas frente a cualquier pretensión de alteración de su naturaleza.

La institución matrimonial es una exigencia ético-antropológica requerida por la autenticidad del amor conyugal; y es también una exigencia del bien común. La razón es transparente: Defender y proteger la institución matrimonial es indispensable desde que el bien del matrimonio está ligado al bien de la familia y a éste el de la sociedad. Defender y proteger la institución matrimonial es una exigencia del bien común. Por tanto, un Estado constitucional de Derecho debe promover una convivencia social sobre la base de unas relaciones de justicia y de solidaridad -de amor, en la terminología cristiana.

Es cierto que el matrimonio se construye sobre los cimientos de la libertad de los que se casan; pero la decisión de construirlo involucra multitud de bienes jurídicos, así como los derechos de los hijos, de la familia y de la sociedad,

Pontificio Consejo Justicia y Paz. Op. cit.

18 Artículo 1.- Defensa de la persona humana.

La defensa de la persona humana y el respeto de su dignidad son el fin supremo de la sociedad y del Estado.

Artículo 2.- Derechos fundamentales de la persona

Toda persona tiene derecho:

A la vida, a su identidad, a su integridad moral, psíquica y física y a su libre desarrollo y bienestar. El concebido es sujeto de derecho en todo cuanto le favorece.

SPIJ (Actualizado al 30 de Marzo de 2011)

19 Ibídem.

20 Cuarta.- Interpretación de los derechos fundamentales.

Las normas relativas a los derechos y a las libertades que la Constitución reconoce se interpretan de conformidad con la Declaración Universal de Derechos Humanos y con los tratados y acuerdos internacionales sobre las mismas materias ratificados por el Perú. SPIJ (Actualizado al 30 de Marzo de 2011).

CONCORDANCIAS: D.S. $\quad \mathrm{N}^{\circ}$ 017-2005-JUS (Aprueban el Plan Nacional de Derechos Humanos 2006-2010 elaborado por el Consejo Nacional de Derechos Humanos) SPIJ (Actualizado al 30 de Marzo de 2011). 
para no mencionar los derechos de los cónyuges, cuya dignidad y naturaleza exceden los contornos de la voluntad de los individuos. Su celebración concierne al bien común y clama siempre un marco público. Nunca puede reducirse a un acuerdo meramente privado. "En concreto, el "sí" personal y recíproco del varón y de la mujer abren el espacio para el futuro, para la auténtica humanidad de cada uno y, al mismo tiempo, está destinado al don de una nueva vida. Por eso, este "sí" personal no puede por menos de ser un "sí" también públicamente responsable, con el que los esposos asumen la responsabilidad pública de la fidelidad, que garantiza asimismo el futuro de la comunidad $»^{21}$

En tanto, para todos los efectos, cada ser humano que está involucrado en esta relación es un fin, nunca un medio. Y esa relación matrimonial, por su propia naturaleza, tiene una dimensión social e institucional que exige que la acción política y legislativa está llamada a salvaguardar los valores de la familia, desde la promoción de la intimidad y la convivencia familiar, hasta el respeto de la vida naciente y la vida que declina; así como la efectiva libertad de elección en la educación de los hijos.

Si se ha de aplicar la cuestión al Derecho de Familia, cabe preguntarse con Benedicto XVI, ¿Cómo podemos reconocer lo que es justo? ¿Cómo podemos distinguir entre el bien y el mal, entre el derecho verdadero y el derecho sólo aparente? ${ }^{22}$ La cuestión es decisiva y ante ella se encuentra también el político y la política misma. En primer término, para regular jurídicamente algún sector de las relaciones sociales, el criterio de la mayoría puede ser un criterio suficiente.

Mas, en las cuestiones fundamentales del Derecho, en las cuales está en juego la dignidad del hombre y de la humanidad, la familia y el matrimonio, el principio de la mayoría de votos o es insuficiente; o es impertinente: En el proceso de formación del Derecho, una persona responsable debe buscar los criterios pertinentes de su orientación.

En mérito a tales atributos, el Estado y la sociedad deben reconocerle protección y tutela. Entre ellos, los atributos que configuran el matrimonio son:

${ }^{21}$ http://www.romereports.com/palio/discurso-de-benedicto-xvi-en-el-parlamento-aleman-como-reconocer-que-esjusto-y-que-es-injusto-spanish-4955.html\#.TnuXWBMJNzY.facebook Consultado en Facebook el 14 de febrero de 2010.

22 http://www.romereports.com/palio/discurso-de-benedicto-xvi-en-el-parlamento-aleman-como-reconocer-quees-justo-y-que-es-injusto-spanish-4955.html\#.TnuXWBMJNzY.facebook Consultado el 01 de noviembre de 2011. 
- La totalidad, en razón de la cual los cónyuges se entregan recíprocamente en todos los aspectos psíquicos, físicos y espirituales que corresponden a la persona;

- La unidad que los hace a los cónyuges " una sola carne »;

- La indisolubilidad de la relación;

- La fidelidad que exige la donación recíproca y definitiva;

- La fecundidad a la que naturalmente está abierto. El desprecio de este rasgo que el mundo actual detenta ya está dando, como producto más ostensible, el envejecimiento poblacional con gravísimas consecuencias sociales y económicas - para mencionar sólo lo estadísticamente obvio. En lo jurídico, este desprecio ha producido normas sociales y legales que conducen a la banalización del matrimonio y de la familia.

La familia natural y el matrimonio son anteriores al Estado y los gobiernos legítimos existen para protegerlos y apoyarlos. El matrimonio, como se ve, no es una franquicia de la sociedad o del Estado, ni es una concesión de la Constitución o del Código Civil; ni del convenio internacional. Tampoco es una imposición desde el exterior en la realidad más privada de cada vida. Por el contrario, es una exigencia intrínseca del pacto conyugal libremente asumido y de la profundidad de la persona humana, que debe ser preservada de toda injerencia indebida. Todo ser humano, desde el recién concebido, tiene derecho a vivir, a crecer, a nacer y a compartir un hogar con sus padres naturales unidos por el matrimonio.

La sociedad no está facultada para disponer del vínculo matrimonial, con el cual los dos cónyuges se prometen fidelidad, asistencia recíproca y apertura a los hijos -para siempre.

La poligamia es una negación radical de su designio original, " porque es contraria a la igual dignidad personal del varón y de la mujer, que en el matrimonio se dan con un amor total y por lo mismo único y exclusivo». El matrimonio, en su verdad «objetiva», está ordenado a la procreación y educación de los hijos. La unión matrimonial, en efecto, permite vivir en plenitud el don sincero de sí mismo, cuyo fruto son los hijos, que, a su vez, son un don para los padres, para la entera familia y para toda la sociedad.

En lugar de promover el divorcio, el Estado debe entender que el matrimonio es entrega recíproca, voluntaria y libre que establece una alianza fundamental en la que los esposos se prometen entrega total, fidelidad y apertura a la vida. El Sínodo de Familia 2014 - 2015 de la 
Iglesia Católica aprobó esta propuesta por una mayoría de 181 votos contra 1 en contra. ${ }^{23}$

\section{DIVORCIO Y POSITIVISMO}

Uno de los íconos omnipresentes de la civilización del espectáculo es la institución del divorcio. En una era en la que el valor prioritario es la diversión, el matrimonio se convierte en algo fuera de lugar. "¿Qué quiere decir civilización del espectáculo? La de un mundo donde el primer lugar en la tabla de valores vigente lo ocupa el entretenimiento, $y$ donde divertirse, escapar al aburrimiento, es la pasión universal..." ${ }^{24}$ La política anti- vida y anti-familia promotora del divorcio ha encontrado que el sexo libre puede ser el entretenimiento fácil, económico y universal con que se puede llenar la cultura- mundo y alejar las masas del cultivo de cualquier valor plausible. Elsublimeinstinto sexualqueha impedido la desaparición de la raza humana ha sido sometido por la civilización del espectáculo. Ha convertido el acto sexual en un pasatiempo, en un deporte frívolo hasta asumir las características de lo que se denomina "sexo libre" o "sexo light". La sola condición que se debe satisfacer es la de proveer de todos los medios y técnicas para evitar la procreación o el incremento de la población. Vargas Llosa encuentra que la banalización del acto sexual lo convierte en sexo "... instintivo y animal. Desfoga una necesidad biológica pero no enriquece la vida sensible ni emocional ni estrecha la relación de la pareja más allá del entrevero carnal; en vez de liberar al hombre o a la mujer de la soledad, pasado al acto perentorio y fugaz del amor físico, los devuelve a ella con una inevitables sensación de fracaso y frustración" 25

En estas condiciones, es coherente con la política, la promoción intensiva del divorcio (y la del aborto). No sólo en el Perú. También en otros países hay esta manifiesta intención política de forjar la sociedad sin familia y sin matrimonio. Como es sabido, en el Perú, pocas son las políticas o las corrientes legislativas que trascienden de un gobierno a otro. Pero, con la política antivida, la política pro-divorcio hace el par de políticas de Estado más estables. No ha sido suficiente la demostración pública de lo opuesto al bien común y a la defensa de los Derechos Humanos que estas políticas son. Se han convertido en pétreas políticas de Estado. Estas políticas han convertido en letra muerta, sin derogarlas, aquellas normas de la Constitución de 1993 que se le oponen, entre las que puede destacarse las siguientes:

\footnotetext{
23 Sínodo de los Obispos. (2014) III Asamblea General Extraordinaria LOS DESAFÍOS PASTORALES DE LA FAMILIA EN EL CONTEXTO DE LA EVANGELIZACIÓN. Instrumentum Laboris. Ciudad del Vaticano. https://www. aciprensa.com/sinodo2014/

24 Vargas Llosa, Mario (2012) La civilización del espectáculo. Pág. 9 Alfaguara.

25 Ibídem.
} 


\section{${ }^{1}$ Artículo 1.- Defensa de la persona humana}

La defensa de la persona humana y el respeto de su dignidad son el fin supremo de la sociedad y del Estado.

\section{Artículo 2.- Derechos fundamentales de la persona}

Toda persona tiene derecho:

1. A la vida, a su identidad, a su integridad moral, psíquica y física y a su libre desarrollo y bienestar. El concebido es sujeto de derecho en todo cuanto le favorece.

SPIJ (Actualizado al 30 de Marzo de 2011)

\section{*Artículo 3.- Derechos Constitucionales. Númerus Apertus}

La enumeración de los derechos establecidos en este capítulo no excluye los demás que la Constitución garantiza, ni otros de naturaleza análoga o que se fundan en la dignidad del hombre, o en los principios de soberanía del pueblo, del Estado democrático de derecho y de la forma republicana de gobierno.

\section{CAPITULO II}

\section{DE LOS DERECHOS SOCIALES Y ECONOMICOS}

\section{Artículo 4.- Protección a la familia. Promoción del matrimonio}

La comunidad y el Estado protegen especialmente al niño, al adolescente, a la madre y al anciano en situación de abandono. También protegen a la familia y promueven el matrimonio. Reconocen a estos últimos como institutos naturales y fundamentales de la sociedad.

La forma del matrimonio y las causas de separación y de disolución son reguladas por la ley. (SPIJ (Actualizado al 30 de Marzo de 2011))

*Cuarta.- Interpretación de los derechos fundamentales Las normas relativas a los derechos y a las libertades que la Constitución reconoce se interpretan de conformidad con la Declaración Universal de Derechos Humanos y con los tratados y acuerdos internacionales sobre las mismas materias ratificados por el Perú. SPIJ (Actualizado al 30 de Marzo de 2011)

CONCORDANCIAS: D.S. $N^{\circ}$ 017-2005-JUS (Aprueban el Plan Nacional de Derechos Humanos 2006-2010 elaborado por el Consejo Nacional de Derechos Humanos) SPIJ (Actualizado al 30 de Marzo de 2011). 
Tal como lo previo Chesterton, "La tendencia actual de la reforma social parece que consiste en destruir todo rastro de los padres." "The Family and the Feud," Irish Impressions) "La familia, como un concepto de grupo, ya ha quedado en un segundo plano; y corre el riesgo de desaparecer del segundo plano." ("The Family and the Feud," Irish Impressions). ${ }^{26}$

Acorde con tales políticas de Estado, la actual legislación trata frívolamente los vínculos matrimoniales y familiares, al promover la destrucción de la familia ${ }^{27}$. Y es mucho más frívola cuando se conoce que la ruptura se convierte en instrumento de chantaje, destrucción o de intimidación que está en poder de uno solo de los cónyuges; se legaliza, judicializa y produce divorcios por la sola voluntad de uno de los cónyuges -en una proporción que supera la ratio de matrimonios.

Este mal, como se sabe no es exclusivo de las sociedades desarrolladas o de las que se hallan en crisis económica. Europa es, tal vez, el continente más duramente golpeado por este flagelo. Llegan desde España el clamor de la frustración: "Los únicos bastiones de resistencia han sido hasta ahora la Iglesia Católica, que por ello conforma el principal enemigo para esta cultura de la muerte, y algunas comunidades cristianas, porque en general la oposición cultural es muy débil, las personas no son conscientes de la manipulación a las que son sometidas..." ${ }^{\prime 28}$ Así se explica la cerril intolerancia de esa cultura contra todo lo que es católico.

Frente a los proyectos hispanos de "divorcio notarial" y "divorcio municipal", hay en España -en alguna medida, aún discreta- el debate que no se llegó a dar en el Perú.

En España, el sector coherente con los principios de defensa de los derechos de la familia, afirma que "la competencia para celebrar un matrimonio no debe amparar la de disolverlo, dado que son realidades absolutamente diferenciadas". La civilización del espectáculo allí y acullá sostiene que la reforma trata de liberar a los jueces de tareas que no son estrictamente jurisdiccionales en las que no haya litigio entre partes, tales como bodas y divorcios, con el fin de descongestionar la Administración de Justicia

26 Citas tomadas de Alquist, Dale (2012). A Prophetic Look. http:/ / www.Chesterton.org/wordpress/tag/dale-ahlquist/ Wednesday, February 22.

27 Ver ley $N^{\circ} 27495$ de 7 de julio del 2001, denominada "Ley que incorpora la separación de hecho como causal de separación de cuerpos y posterior divorcio". También la ley N²9227, denominada "Ley que regula el procedimiento no contencioso de la separación convencional y divorcio ulterior en las municipalidades y notarías" de 16 de mayo del 2008.

28 http://www.hazteoir.org/noticia/56808-arsuaga- Consultado el 25 de febrero de 2014. 
para que determinados asuntos sean resueltos por otros operadores como notarios, registradores y secretarios judiciales.

Mientras se denuncia el gran daño que, junto a la falta de ayudas públicas, está ocasionando el divorcio expréss a la familia en España, el Estado autorizará matrimonios y divorcios ante notario a través de una reforma del Código Civil que incluirá la futura Ley de Jurisdicción Voluntaria, fijando un arancel de 95 euros por enlace. Pero el ministro de Justicia, Alberto Ruiz-Gallardón, anunciaba la aprobación que "permitirá agilizar las listas de espera del Registro Civil con un coste asumible dentro del coste general de celebración de una boda". En el caso del divorcio, Ruiz-Gallardón ha reiterado que únicamente podrá hacerse ante notario en los casos en los que no existan menores y exista mutuo acuerdo entre los dos cónyuges, ya que se trata de casos en los que el convenio regulador no contempla la intervención del fiscal. ${ }^{29}$

El Dr. Jaime Arenas Martínez, magistrado de la Corte Superior de Justicia de Arequipa, comenta que "Ruiz- Gallardón, justifica esta reforma en que nada sale del ámbito de lo público" y que se trata simplemente de "una nueva oferta de servicios" nos preguntamos, ¿qué concepción tienen del matrimonio? Comentario aparte es que en nuestro país rige la ley 29277, la que no ha merecido ninguna justificación y permite el divorcio incluso de matrimonios con hijos menores. En buena hora el pronunciamiento de rechazo del Consejo del Poder Judicial español".

\section{FRIVOLIDAD, EUFEMISMOS Y SUPERSTICIÓN}

En materia de involuciones legales en el terreno de los derechos de la familia, hay corrientes que van paralelas en diversos países. Como en España y otros países de habla hispana, la jerga legal peruana también viene aderezada de aquellos eufemismos con los que la cultura de la muerte, aviesa, adereza el léxico para hacer digeribles las más perversas realidades. De esta forma, "aborto terapéutico" es el nuevo nombre del antiguo y pingüe negocio del aborto cuasi despenalizado que se practica con cualquier pretexto pseudo médico y que no tiene ninguna finalidad terapéutica. El matrimonio está a punto de desaparecer y para este efecto los sustantivos cónyuge, amante, relación adúltera, o conviviente son todos ecualizados y se le reemplaza por el eufemismo "pareja" que cobija a todos o a cualquiera de los nombrados. 29 Ver http://www.hazteoir.org/noticia/56799- cgpj-propone-gallardon-que-jueces-y-no-notarios-mantengan-
control-separaciones-y Consultado el 25 de febrero de 2014 . 
Entre los eufemismos más aberrantes se encuentran los llamados divorcio por mutuo acuerdo, divorcio notarial y divorcio municipal; nombres con los que se designa al quiebre del compromiso matrimonial libremente suscrito, con la correspondiente legalización del abandono del hogar.

Los "justiciables" y los "operadores" prefieren denominarlos con las etiquetas internacionales de "divorcio expréss", "divorcio a la carta", "divorcio delivery". La ley sólo ha definido y priorizado el divorcio frívolo. También la legislación ha devenido frívola. Mario Vargas Llosa hace recordar que "... el diccionario llama frívolo a lo ligero, veleidoso e insustancial, pero nuestra época ha dado a esa manera de ser una connotación más compleja. La frivolidad consiste en tener una tabla de valores invertida o desequilibrada en la que la forma importa más que el contenido, la apariencia más que la esencia y en la que el gesto y el desplante - la representación- hacen las veces de sentimientos e ideas." ${ }^{30}$

Esta legislación contraria al bien común, se dirige desenfrenadamente al establecimiento de una sociedad sin familias; rinde culto a la civilización del espectáculo, con desprecio de la realidad espiritual, psicobiológica y social subyacente, de la experiencia acumulada en la materia a través de los siglos. El divorcio no arregla ningún problema sino que agrava los que según la propaganda política- trata de resolver. El lacerante problema de la ruptura afecta no sólo a los cónyuges que rompen su compromiso sino que afecta también a cada vez un mayor número de hijos. Los hijos han sido y son- los grandes e inocentes perjudicados con la ruptura conyugal. Para confrontar la cultura de ruptura actual se hace necesario generar una cultura de reconciliación de la que ningún político dice nada.

La civilización del espectáculo enarbola la superstición ${ }^{31}$ de un mundo idílico en el que esa felicidad sólo puede ser alcanzada a partir del momento en que un funcionario público pronuncia las palabras cabalísticas del divorcio. El énfasis en la búsqueda de la felicidad personal condiciona la visión del matrimonio, y en concreto la actitud con la que se debe afrontar las tensiones e insatisfacciones de la vida matrimonial. La cultura individualista y egoísta, llevada a estos extremos infames, ha acarreado el divorcio considerado como salida personal a la insatisfacción personal, real o aparente, sin tener en cuenta las consecuencias para otros, especialmente para los hijos, para la familia y para la sociedad. Mientras que el Estado esté a cargo de la Educación, no

Vargas Llosa, Mario (2012) La civilización del espectáculo. Lima : Alfaguara. p 14.

G. K. Chesterton acuñó esta frase en su excelente colección de ensayos La Superstición del Divorcio. 
enseñamos nada, dice Chesterton, "y el mismo tipo de nada, a todos. Porque a lo que obligamos a todas las familias, por el poder de la policía, no es a una filosofía, sino al arte de leer y escribir sin filosofía." (Illustrated London News, 3 oct, 1931) citado por Ahlquist ${ }^{32}$.- En el Perú, no es tanto que se enseñe una filosofía no adecuada como que no se enseñe ninguna. Y no es que no se ofrezca Educación Sexual, sino que se impone una pseudo educación acorde con el empecinamiento en buscar el placer hedonístico.

Otra arma con la que cuenta la defensa de la superstición del divorcio es el Positivismo: Tal como se repite en el aula universitaria, la visión positivista del mundo fue una de las grandes e irrenunciables expresiones de la creatividad humana; afirmando también que, hoy en día, por ella misma, esta visión resulta insuficiente para el logro de la justicia y la paz social. La razón positivista no es el todo del universo cultural humano, pues sólo percibe aquello que es funcional. Por tanto, sería erróneo considerar que la razón positivista sea la única cultura válida, relegando todas las otras realidades culturales a la condición de subculturas; o al positivismo como único y exclusivo fundamento común para la formación del Derecho, mientras son lamentablemente preteridas todas las otras convicciones y los otros valores de la cultura.

Es necesario superar esa frívola visión positivista para acercarse a la naturaleza en toda su profundidad, requerimientos y globalidad. Al iniciarse el s. XXI, el matrimonio y la familia sufren los embates de la prepotencia de la opinión pública manipulada, y de las arbitrariedades del poder. Sus victorias se hacen palpables: Matrimonio y familia están en peligro de extinción. Se siente ya la presencia de la sociedad sin familia y sin matrimonio.

\section{EL DIVORCIO Y LOS POLÍTICOS}

"Una concepción positivista de la naturaleza, que comprende la naturaleza en modo puramente funcional, como las ciencias naturales la explican, no puede crear ningún puente hacia el Ethos y el Derecho, sino suscitar nuevamente sólo respuestas funcionales. Sin embargo -afirma Benedicto XVI - lo mismo vale también para la razón en una visión positivista, que muchos, lamentablemente, consideran como la única visión científica. En ella, aquello que no es verificable, lucrativo o placentero no entra en el ámbito de la razón en sentido estricto. Desde ese punto de vista, el ethos y la religión deben ser

32 Alquist, Dale (2012) A Prophetic Look. Disponible en internet: http://www.Chesterton.org/wordpress/tag/daleahlquist/ Consultado el 22 de febrero de 2012. 
reducidos al ámbito de lo subjetivo y caen fuera del ámbito de la razón en el sentido estricto de la palabra. Donde rige el dominio exclusivo de la razón positivista - y este es en gran parte el caso de nuestra conciencia pública - las fuentes clásicas de conocimiento del ethos y del Derecho quedan fuera de juego. Ésta es una situación dramática que interesa a todos y sobre la cual es necesaria una discusión pública..." 33

"Servir al derecho y combatir el dominio de la injusticia es y sigue siendo el deber fundamental del político. En un momento histórico, en el cual el hombre ha adquirido un poder hasta ahora inimaginable, este deber se convierte en algo particularmente urgente. El hombre tiene la capacidad de destruir el mundo. Se puede manipular a sí mismo. Puede, por decirlo así, hacer seres humanos y privar de su humanidad a otros seres humanos que sean hombres." ${ }^{34}$

La invocación que hace el Papa Emérito también está dirigida a los políticos y a los líderes de opinión en los ámbitos de la política familiar desde que no es la ley ni la convención social; es el amor (en el sentido de amor/ágape de la filosofía clásica) la piedra fundamental de la familia y del matrimonio.

Las campañas de demolición de la familia y del matrimonio ya han dado los frutos que se puede palpar en la apatía de la sociedad y de la educación frente a esas instituciones. Esta apatía ha abierto las puertas para que el legislador reescriba los derechos de la familia y del matrimonio. De esta forma, la legislación refuerza el poder político con la secuela del triunfo de una forma de despotismo ilustrado o no, pero que acarrea el monismo en lo jurídico y en lo político; una racionalidad deductiva y lineal. Y, lo que, en el caso de las instituciones del matrimonio y la familia, es más temible, la legislación codificada, en la era de la complejidad, arrastra una concepción del tiempo orientado hacia un futuro controlado, fiel a la superstición del progreso de la historia: la idea de que la ley -anticipando un estado de cosas posible y considerado preferible- puede hacer llegar un porvenir mejor

Pese a todo, aún se puede pedir a los legisladores que no ignoren que la norma positiva debe nutrirse de las propias enseñanzas milenarias de la humanidad que ha reconocido que la familia natural es la unión de un varón y una mujer a través del matrimonio, creada con el fin de compartir el amor y la alegría, engendrar niños, proveer su educación moral, ser primera escuela 
de democracia, ser primera escuela de democracia, ser primera escuela de democracia, construir una economía doméstica, ofrecer seguridad en tiempos de crisis y unir a las generaciones. Y que la familia natural es un elemento fijo, arraigado en la naturaleza humana. La familia natural no puede convertirse en una realidad de nueva creación, ni puede ser re-definida por los entusiastas de la ingeniería social.

Esta perspectiva lleva a considerar necesaria la adecuación del Derecho Positivo a la ley natural. La política familiar así planteada reconoce estabilidad y la indisolubilidad de la unión matrimonial que no deben quedar confiadas exclusivamente a la intención y al compromiso de los individuos: la responsabilidad en el cuidado y la promoción de la familia, como institución natural y fundamental, -precisamente en consideración de sus aspectos vitales e irrenunciables- compete principalmente a toda la sociedad. La necesidad de conferir un carácter institucional al matrimonio, fundándolo sobre un acto público, social y jurídicamente reconocido, deriva de exigencias básicas de naturaleza social.

"Como el Estado ha sustituido a la familia como autoridad principal, y ha sustituido a cualquier otra autoridad secundaria que solía tener algo de autoridad propia, es el Estado el ente que debe remediar todos los resultados absurdos que se produce, y esto debe hacerse a través de los Tribunales de Justicia." (Illustrated London News 24 de marzo, 1923).

Hay un barniz cultural e histórico ligado a las formas de las relaciones sociales que se desprenden de un dato natural. Las relaciones sociales siguen fundándose en la naturaleza.

\section{REFERENCIAS Y SITIOS WEB CONSULTADOS}

Ahlquist, Dale (2012) Seeing With the Eyes of G.K. Chesterton | An Interview with Dale Ahlquist Diponible en internet:

http://www.Chesterton.org/wordpress/tag/dale-ahlquist/ Consultado el 29 de febrero de 2012.

Alquist, Dale. (2012) A Prophetic Look. Disponible en internet: http:// www.Chesterton.org/wordpress/tag/dale-ahlquist/ Consultado el 22 de febrero de 2012 
Benedicto XVI, (2011) Discurso ante el Parlamento Alemán. Disponible en internet: http://www.romereports.com/palio/discurso-de-benedictoxvi-en-el-parlamento-aleman-como-reconocer-que-es-justo-y-que-esinjusto-spanish-4955.html\#.TnuXWBMJNzY.facebook Consultada el 01 de noviembre de 2011

G. K. Chesterton (1920) La superstición del Divorcio (The Superstition of Divorce). En Obras completas, tomo I; Barcelona: Plaza \& Janés, 1967; 1676 pp., de la p. 871 a la p. 936; trad. de Eduardo Toda Valcárcel. Nueva edición en Sevilla: Los Papeles del Sitio, 2008; 144 pp.; trad. de Aurora Rice Derqui; prólogo de Enrique García Máiquez; ISBN 13: 97884-935892-5-7 Disponible en internet: http://www.Chesterton.org/ wordpress/tag/dale-ahlquist/ Consultado el 22 de febrero de 2012

Orwell, George.(1984) Nineteen eighty four. En: http://www.georgeorwell.org/1984

Pontificio Consejo "Justicia y Paz" (2005) Compendio de la Doctrina Social de la Iglesia. Librería Editrice Vaticana. www.libreriaeditricevaticana.com Conferencia Episcopal Peruana. Asociación Hijas de San Pablo. San Juan de Lurigancho. Lima, Perú.

Rubio Correa, Marcial. (2002) Para conocer la Constitución Política del Perú. Fondo Editorial PUCP. Lima.

Sínodo de los Obispos (2014) III Asamblea General Extraordinaria Los Desafíos Pastorales de la Familia en el contexto de la Evangelización. Instrumentum Laboris. Ciudad del Vaticano. Disponible en internet: https://www. aciprensa.com/sinodo2014/ Consultado el 22 de diciembre de 2014

Fecha de recepción : 28 de agosto de 2014

Fecha de aceptación : 30 de setiembre de 2014 
